\title{
Integrated Direct and Indirect Flood Risk Modeling: Development and Sensitivity Analysis
}

\author{
E. E. Koks, ${ }^{1, *}$ M. Bočkarjova, ${ }^{2}$ H. de Moel, ${ }^{1}$ and J. C. J. H. Aerts ${ }^{1}$
}

\begin{abstract}
In this article, we propose an integrated direct and indirect flood risk model for small- and large-scale flood events, allowing for dynamic modeling of total economic losses from a flood event to a full economic recovery. A novel approach is taken that translates direct losses of both capital and labor into production losses using the Cobb-Douglas production function, aiming at improved consistency in loss accounting. The recovery of the economy is modeled using a hybrid input-output model and applied to the port region of Rotterdam, using six different flood events (1/10 up to $1 / 10,000)$. This procedure allows gaining a better insight regarding the consequences of both high- and low-probability floods. The results show that in terms of expected annual damage, direct losses remain more substantial relative to the indirect losses (approximately 50\% larger), but for low-probability events the indirect losses outweigh the direct losses. Furthermore, we explored parameter uncertainty using a global sensitivity analysis, and varied critical assumptions in the modeling framework related to, among others, flood duration and labor recovery, using a scenario approach. Our findings have two important implications for disaster modelers and practitioners. First, highprobability events are qualitatively different from low-probability events in terms of the scale of damages and full recovery period. Second, there are substantial differences in parameter influence between high-probability and low-probability flood modeling. These findings suggest that a detailed approach is required when assessing the flood risk for a specific region.
\end{abstract}

KEY WORDS: Flood duration; flood risk modeling; indirect losses; input-output model

\section{INTRODUCTION}

Numerous studies in the area of natural disasters have developed approaches to model and estimate consequences of flooding. Many of these studies, often originating from the engineering community, address primarily the direct losses (i.e., destruction of physical and human capital) of flooding based on detailed flood simulations. ${ }^{(1-4)}$ The estimation of indirect losses (i.e., production losses due to

\footnotetext{
${ }^{1}$ Institute for Environmental Studies (IVM), VU University Amsterdam, Amsterdam, The Netherlands.

${ }^{2}$ Department of Spatial Economics, VU University Amsterdam, Amsterdam, The Netherlands.

*Address correspondence to Elco Koks, VU University Amsterdam, De Boelelaan 1087, 1081 HV Amsterdam, The Netherlands; tel: +31 2059 83129; elco.koks@vu.nl.
}

interruption of economic processes in and outside the affected area), on the other hand, has mainly been the domain of the economic community, using models such as input-output (I-O), computable general equilibrium (CGE), or hybrid models based on a specific disaster event. ${ }^{(5-9)}$ A few studies have proposed a more integrative approach for the calculation of both direct and indirect flood damage. For instance, Jonkman et al. ${ }^{(10)}$ proposed an integrated framework for the combination of direct and indirect losses, and FEMA ${ }^{(11)}$ developed two modules within the HAZUS-FLOOD model to assess direct- and indirect losses in the United States. However, in our opinion, an integrative model with the capacity to dynamically incorporate various elements of flood damage assessment, such as the flood hazard, the 
direct damages, and the total economic effects, is still lacking. In particular, existing models often fall short of systematic estimation of direct and indirect losses and provision of a coupling between the two. In this study, we attempt at closing this gap.

In this article, we propose a framework for a dynamically integrated direct and indirect flood risk model and operationalize it for the Rotterdam (the Netherlands) harbor area. The framework consists of multiple steps and includes elements salient to integrative loss estimation. First, based on flood maps, a direct loss assessment is conducted in the harbor area, with a detailed differentiation between various industrial sectors. Second, we show how direct losses in both capital and labor can be translated into the loss in production per sector in a consistent manner by making use of a Cobb-Douglas production function. In this regard, labor losses are of particular importance for large (low-probability) floods, which may involve human victims. Third, we model production losses for the time period when the area is still flooded and therefore unable to begin recovery. Fourth, the recovery of production after the shocks is modeled using a hybrid I-O model to estimate the short-term economic effects, using different simulated flood events. Ultimately, the model outcome is loss estimation expressed in terms of expected annual damage (EAD). This model is a ready-to-use tool that can assist both researchers and practitioners in flood vulnerability analysis and well-informed decision making.

Furthermore, we perform an extensive sensitivity analysis (SA) of the model. In particular, we explore parameter uncertainty using a global SA. Next to that, we vary critical model parameters related, among others, to labor recovery and flood duration, using a scenario approach. This SA provides critical insights for the methodological and empirical domains of damage modeling and exemplifies the uncertainties intrinsic to indirect damage modeling. Moreover, the sensitivity results can be used to compare existing indirect damage models and their outcomes, assist in modeling practice such as warranting of model assumptions, and direct future research needs.

The remainder of this article proceeds as follows. In Section 2, an extensive explanation is given of the proposed flood risk model and in Section 3, an explanation of the SA is provided. In Section 4, an overview is provided of the used data. In Section 5, we present and discuss the results of the direct and indirect flood risk estimates, and the associated uncertainty analysis (UA) and sensitivity analysis (SA). In Section 6, final conclusions are drawn.

\section{FLOOD RISK MODEL}

Flood risk can be defined as a function of the hazard's probability, the exposure, and the vulnerability of the exposed socioeconomic system ${ }^{(12,13)}$ and in engineering literature is often expressed in terms of EAD. The EAD is defined as the sum of the expected value of damages that might be caused by a set of flood events, or as the integral below the probability-loss curve. ${ }^{(14)}$ While being an insightful concept, EAD is rarely met in economic literature, where often analysis of a specific disaster event (such as the Kobe earthquake ${ }^{(15)}$ or Hurricane Katrina ${ }^{(7)}$ ) or some "typical" disaster event is presented. In this article, we shall use the concept of EAD and apply it to an integrative flood risk model (this section) and consider a spectrum of flood events in the Netherlands to test the model (Section 5).

In disaster modeling literature, a large variety of definitions for both direct and indirect losses are used. $^{(6,16,17)}$ To avoid ambiguity, we will provide definitions of direct and indirect losses as will be used in this article in line with Bočkarjova et al. ${ }^{(18)}$ Direct losses will be considered as stock input losses and indirect losses as flow output losses. In this respect, stock input losses refer to material damages and include the existing level of capital, facilities, and inventories of products, whereas flow output losses refer to outputs and services of stocks over time.

Direct losses are usually calculated with the use of depth-damage functions. ${ }^{(10,19)}$ Indirect losses, on the other hand, require a different modeling approach due to the interaction of multiple economic actors that emerge in an economy at large. The most commonly used and well-documented approaches in economic disaster modeling are I-O and CGE modeling. ${ }^{(20)}$ Due to explicit representation of production technology and interindustry dependencies, direct interpretability, and data availability, I-O models are well suited for assessing how the effects of a (natural) disaster propagate into the economy through intermediate consumption

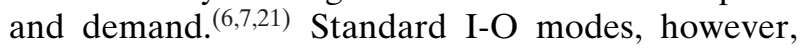
have a number of shortcomings. First, they often overestimate the results due to linearity and the lack of substitution possibilities within the production system. Second, I-O models only assess the disaster shock on the demand side of the economy, i.e., consider backward-linked losses. Third, I-O models 
have a lack of interdependence between price and output and a lack of explicit resource constraints. ${ }^{(16)}$ Recently, however, a number of hybrid I-O models have been presented ${ }^{(7,8,22)}$ that address a number of I-O disadvantages and, similar to CGE, allow more flexibility. Besides, I-O-based models are relatively easy to combine with models that contain, for example, a more detailed description of the water cycle, such as hydroeconomic models. ${ }^{(16)}$ Finally, because the availability of I-O tables makes I-O-based approaches readily usable, we shall use an I-O framework and present a model that extends it, based on Bočkarjova $^{(23)}$ and Hallegatte. ${ }^{(24)}$ Besides, we test the sensitivity of model results to uncertainty (see Section 3). This helps to identify possible limitations in the model and more detailed data needs, as well as provide a basis for a more complete interpretation of model results and the model assumptions.

Fig. 1 presents an overview of the methodological framework. In the first stage, a direct loss assessment is conducted, ${ }^{(25)}$ where we specifically focus on the various industries of the study area. Second, we show how direct losses in both capital and labor can be translated into loss in production per sector in a consistent manner by making use of a Cobb-Douglas production function. This production loss is used to calculate the imbalanced postdisaster economic situation, by making use of the basic equation (BE). ${ }^{(23)}$ We note that we allow for a prerecovery period for the duration of the flood.
The final step of the model is the recovery of the economy and reconstruction of the area. This final step is modeled by using an adapted hybrid I-O model, based on the adaptive regional input-output (ARIO) model. ${ }^{(7,24)}$ Overall, the presented framework requires only three inputs, making it widely applicable: an inundation map, a land-use map, and an I-O table.

\subsection{Direct Loss Assessment}

The most common methodology for direct damage assessments is the use of depth-damage functions. ${ }^{(26)}$ This approach calculates damage using spatial information on land-use classes or building types (the exposure) and inundation depths (the hazard). For each building type or land-use class, a maximum value at risk $\left(D^{\max }\right)$ and a depth-damage function $(\alpha(h))$ are assigned (Fig. 2). A depthdamage function indicates what fraction of total value at risk is damaged at different inundation depths. In each cell, fraction $(\alpha)$ of total damage is then determined for each building type and land-use class based on the inundation depth $(h)$ for a particular flood event. Obtained damages for all cells are then aggregated to arrive at the total direct damage of the flooded area $\left(D^{d i r}\right)$. Equation (1) presents the formula for assessing this total direct damage, where $m$ is the number of land-use categories $(l)$ and $n$ the number of cells $(r)$ in the flooded area. ${ }^{(10)}$ The

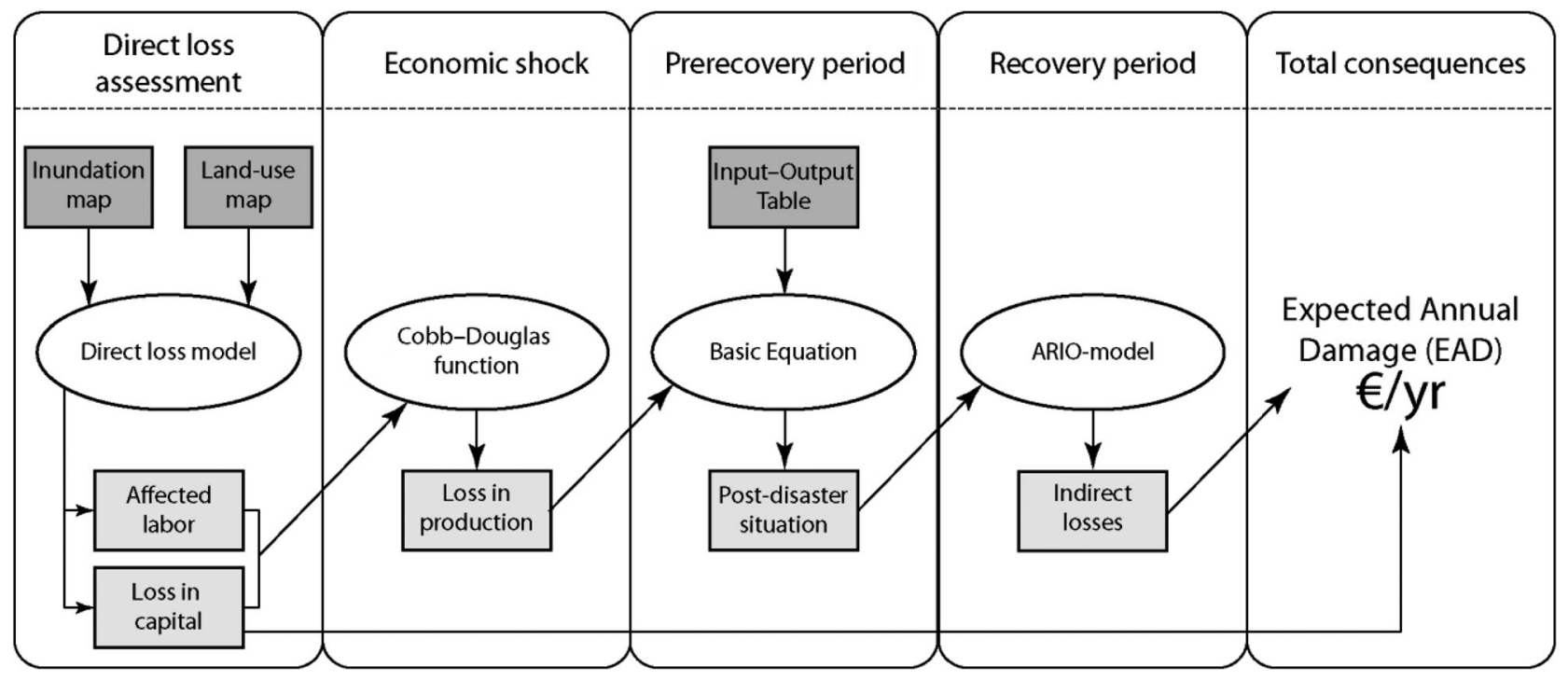

Fig. 1. Overview of the different components of the framework. The dark gray squared boxes are the inputs, the ellipses are the different models, and the light gray squared boxes are the model outputs. 


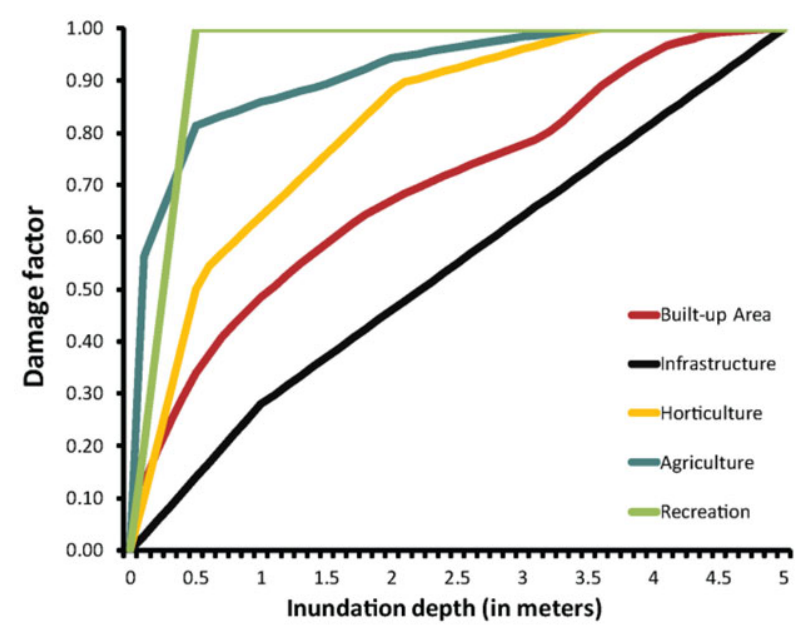

Fig. 2. Examples of various depth-damage curves used in the direct loss assessment.

maximum damages and depth-damage curves used in this study are based on De Moel et al. ${ }^{(25)}$ However, to improve the precision of direct damage estimates, we extend the approach of De Moel et al., ${ }^{(25)}$ where two industrial classes are used, by distinguishing 16 different industrial classes in the harbor area, for which the maximum damages and depth-damage curves are based on Tebodin. ${ }^{(27,28)}$ For a more elaborate explanation of the direct loss assessment, please refer to De Moel et al. ${ }^{(25)}$

$$
D^{d i r}=\sum_{l}^{m} \sum_{r}^{n} \alpha\left(h_{r}\right) D_{l}^{\max },
$$

where $D^{d i r}$ is total direct damage in the area under consideration, $D^{\max }$ is value at risk for land- use category $i, \alpha_{i}\left(h_{r}\right)$ is depth-damage function for land- use category $i$, and $h_{r}$ is hydraulic characteristics (water depth) of the flood in a particular cell $r$.

\subsection{From Direct Losses to Production Losses}

While in disaster modeling direct damages to capital assets are often assumed to directly reflect production losses, such a one-to-one transformation is too raw. Although allowing a straightforward proxy, such approaches however ignore the production process that transforms various inputs and production factors into the final products. Therefore, to link estimates of direct flood damage in capital and labor to the economic shock in this model, we use a Cobb-Douglas production function. ${ }^{(29)}$ A standard Cobb-Douglas production function as in Equation (2) translates the use of production factors capital $(K)$ and labor $(L)$ to produce the amount of final goods $(Y)$ in each sector $j$. Furthermore, $b$ is the total factor productivity (a scaling parameter) and $\alpha$ and $\beta$ are output elasticities indicating by how much final output would change if capital and labor endowments change by one unit, respectively.

$$
Y_{j}=b_{j} K_{j}^{\alpha} L_{j}^{\beta} .
$$

Within an I-O framework, labor and capital belong to the value-added part of the table, and together with intermediate inputs, they make up, columnwise, the total production per sector (see Table I). So, essentially, Equation (2) can tell us the amount of value added if capital and labor are known. This interpretation of the CobbDouglas function becomes a useful tool in determining changes in value added ( $Y_{j}$ in Equation (2)) when changes in capital and labor become known. From the direct loss estimation as described in Section 2.1, direct damages per industry are available $\left(D^{d i r}\right.$ in Equation (1)), which we assume are losses of capital goods. Furthermore, we assume that labor is evenly distributed among the sectors, so that the share of industry flooded is approximated to a loss in labor per sector. In future work, a model estimating the loss of life such as Jonkman et al. ${ }^{(10)}$ can be easily incorporated to refine the labor loss estimates as it uses an inundation map as input requirement, similarly to the direct loss module described above. Inserting loss of capital and labor in Equation (2) will thus yield the loss in value added as a result of flood.

We note that our approach addresses the issue of underestimation of production losses that is often signaled by disaster modelers ${ }^{(30)}$ when translating direct damages into the loss in value added. In this regard, several steps are taken for this translation. First, by accounting for the loss of both capital and labor as described above; second, by calibrating industryspecific elasticities ( $\alpha$ and $\beta$ ) when translating direct damages to production losses; and third, by adopting the assumption of constant returns to scale. We will elaborate on the second and third steps below. To reflect production processes within an economy more precisely, we calibrate parameters $\alpha, \beta$, and $b$ for each industrial sector based on the predisaster I$\mathrm{O}$ table, which is assumed to reflect markets in equilibrium. Therefore, $Y, K$, and $L$ are directly available from the I-O table, where $K$ is returns to capital, $L$ is labor costs or wages, ${ }^{(31)}$ and $Y$ is the total value added of a specific sector $j$ (see Table I). 
Table I. General Framework of an Input-Output Table

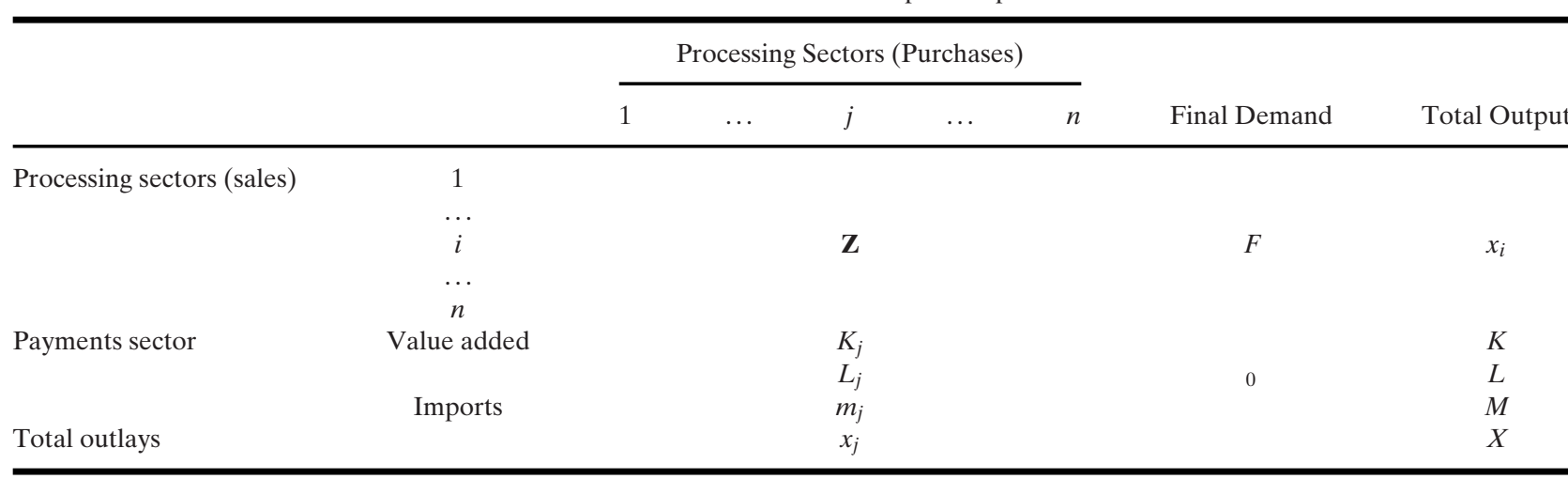

Standard economic models of growth ${ }^{(32)}$ assume that production processes reveal decreasing returns to scale, so that in equilibrium the "last" unit of input (be it capital or labor) is the least productive compared to the "first" units of input. Alternatively, we assume a Cobb-Douglas function with constant returns to scale (i.e., $\alpha+\beta=1$ ). This assumption allows representing an "average" productivity of each unit of input throughout the production process, which is the same for all production units. Because flood disasters affect different units of input independently of their productivity, constant returns to scale will treat all input units of labor and capital to be equally productive, thus correcting for a possible underestimation of production losses. This assumption will also apply during the recovery, where constant returns to scale will treat production factors to be, on average, equally productive throughout the entire recovery process (we shall return to this in Section 5.3).

The following procedure is applied. As a first step, we translate direct losses of capital and labor to losses in value added using the Cobb-Douglas function, where $\Delta K$ is the remaining capital and $\Delta L$ is the remaining labor:

$$
\Delta Y_{j}=Y_{j}-\left[b_{j}\left(\Delta K_{j}^{\alpha}\right)\left(\Delta L_{j}^{\beta}\right)\right] .
$$

We note that this is a column-wise operation in I-O terms. Next, losses in sectoral value added $\left(\Delta Y_{j}\right)$ are related to total outlays, i.e., they are redefined in terms of reduced sectoral outlays, or a "shock." Assuming a stable relationship between the sectoral value added $\left(Y_{j}\right)$ and total outlay $\left(X_{j}\right)$, the economic shock per sector $\left(s_{j}\right)$, can be obtained as shown in Equation (4):

$$
s_{j}=\frac{Y_{j}}{X_{j}} * \frac{\Delta Y_{j}}{Y_{j}} .
$$

The shock $s_{i}$ is thus defined as the inoperability of a specific sector, which is the percentage that a specific sector cannot fulfill of the as-planned level of production. ${ }^{(33,34)}$ Equation (4) shows that, effectively, due to a fixed relationship between $Y_{j}$ and $X_{j}$ for each sector (which we will also assume to be fixed for each sector during the recovery period due to the same production function), changes associated with losses of value added $\left(\Delta Y_{j}\right)$ can be translated into a measure of sector inoperability. ${ }^{(35)}$ In other words, this ratio describes how the outlay of a particular sector is dependent upon the value added. ${ }^{(36)}$ We recall that an I-O table features the balance between $X_{j}$ (total outlays) and $X_{i}$ (total outputs) so that $\sum_{i=1 . . n} X_{i}=\sum_{j=1 . . n} X_{j}$ (see Table I), both of which represent total sectoral production. Therefore, in defining the shock, column-wise changes in value added $(\Delta Y j)$ can be related to row-wise changes in total output $\left(X_{i}\right)$. This makes it possible to rewrite $s_{j}$ 's into $s_{i}$ s. Consequently, row-wise sectoral shocks $s_{i} \mathrm{~s}$ can be expressed as an economy-wide inoperability matrix, defined as $\sigma$ (Equation (5)).

$$
\sigma=\left[\begin{array}{cccc}
1 & \cdots & \cdots & 0 \\
\vdots & \ddots & 0 & \vdots \\
& & & \\
\vdots & 0 & \ddots & \vdots \\
0 & \cdots & \cdots & 1
\end{array}\right] *\left(\begin{array}{c}
s_{1} \\
\cdot . \\
s_{i} \\
s_{i+1}
\end{array}\right) .
$$

Alternatively, a matrix of remaining production capacity $(1-\sigma)$ can be obtained as: 


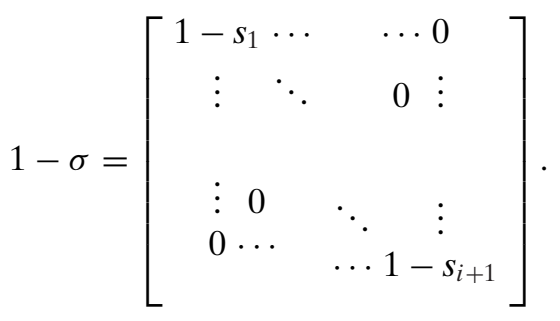

\subsection{Prerecovery Period}

After the economic shock is defined, the next step is to assess the production loss in the period directly after the flood. Floods in recent history (e.g., the floods in central Europe in 2002 and 2013) have shown that it can take a long time before all the water recedes. Thus, for the period of flood duration, everyday routines are distorted, firms are not able to produce, and reconstruction cannot begin. It is important to note that, due to the different types of floods and different characteristics of areas prone to flooding, assumptions about flood duration may vary substantially across the areas, and may lead to a high variability in model parameters related to flood duration (as will be discussed in Sections 3 and 5). A flood occurring in the outer dike areas is a short-lived event compared, for instance, to a flood occurring in a polder area, where it can take up to several months before all the water is pumped out. ${ }^{(37)}$

A standard I-O model, as in Equation (7), describes a relation between final demand, $F$ (consisting of exports, stocks, the final demand of households and governments), and total output $(X)$ where $A$ is the matrix of interindustry inputs that are necessary to produce goods to satisfy final demand. ${ }^{(38)}$ In the short run, proportions between interindustry inputs are assumed to be stable, and represent therefore prevailing interindustry technology:

$$
X=A X+F .
$$

To reflect the state of an economy directly after a shock and to obtain production loss in the postdisaster situation, we make use of the BE. ${ }^{(6)}$ This BE proposes that it is essential to postdisaster modeling to have an account of an economy directly after the shock. The main motivation for this is that an economy affected by a major stress is out of equilibrium, i.e., established relations between sectors are seriously disturbed and cannot function normally and therefore cannot satisfy the needs of intermediate sectoral demand as well as final demand. This state is a starting point for recovery where an economic system needs to find its new balances. We shall briefly explain how a BE is derived.

For the derivation of a $\mathrm{BE}$, a predisaster economy is first represented in terms of production inputs $(A)$, total output (vector $X$ ), final demand in terms of real wages (matrix $F / L$ ), and labor force (scalar $L$ ) that is distributed among the sectors (transposed vector $l^{\prime}$ of sectoral labor intensities). The predisaster economy is in balance and is represented in Equation (8):

$$
\left[\begin{array}{cc}
A & F / L \\
l^{\prime} & 0
\end{array}\right]\left(\begin{array}{l}
X \\
L
\end{array}\right)=\left(\begin{array}{l}
X \\
L
\end{array}\right) .
$$

Or simply rewritten into:

$$
M q=q .
$$

Next, we introduce a shock to the left-hand side of the equation defined by $\sigma(1-\sigma)$. as in Equation (5). The remaining part of a postcalamity system can be then described as:

$$
(1-\sigma) * M * q=t
$$

Equation (10) is referred to as a BE, where $(1-\sigma)$ is the matrix of remaining sector capacities (Equation (6)). The distinct feature of BE is that the interim vector $t$ is not a vector of total output, but a mere row-wise sum of remaining assets, which, due to disproportions in sectoral losses, do not yet make up a working system (for an extensive explanation of the BE, see Steenge and Bočkarjova ${ }^{(6)}$ and Bočkarjova et al. ${ }^{(18)}$ Because part of inputs for some production sectors cannot be delivered as a result of flood losses incurred by suppliers, other inputs become partly redundant in the production process, thus forcing the sectors to reduce or even temporarily cease production. Due to the fact that not all available resources can be directly used in production (but perhaps can be used as stock or export), the new total output for a recovering system (say, a new vector $X_{\text {new }}$ ) would expectedly be lower than vector $t\left(X_{\text {new }}<t\right)$. Thus, the BE as in Equation (10) contains the necessary postcatastrophe information on the disproportions, where disproportionality is defined in terms of a distorted predisaster economic connection and inability of total output to directly meet the final demand needs. At this stage, vector $t$ will be used as a starting point for modeling postdisaster recovery in the process of reaching a new equilibrium. As a baseline case, we assume that interindustrial relations and thus technological coefficients (matrix $A$ ) are not changed after the shock and therefore remain similar to the predisaster situation. Thus, the aim of recovery 
efforts is to achieve such levels of interindustrial outputs that the system reaches the satisfaction of predisaster level of final demand. We define the prerecovery losses (PRLs) per sector before the start of recovery as:

$$
P R L_{j}=\frac{Y_{j}^{0}-Y_{j}^{p d}}{365} * T^{\text {flood }},
$$

where $T^{\text {flood }}$ is the number of days the area cannot recover yet, $Y_{j}^{0}$ the sectoral value added in the predisaster situation, and $Y_{j}^{p d}$ the sectoral value added in the postdisaster situation. The parameter $T^{\text {flood }}$ is dependent on the location and type of area where the flood occurs.

\subsection{Recovery Period}

After the water has receded and the area is accessible again, reconstruction of the area can begin. For the recovery period, use is made of the ARIO model. ${ }^{(7,24)}$ In this article, we will use the latest version of the ARIO model as a starting point, as proposed in Hallegatte. ${ }^{(24)}$ The ARIO model is I-O based, modeling economic adjustments in response to a natural disaster. The ARIO model considers the regional economy consisting of households and various industries that exchange, import, produce, and export goods and services. It accounts for interactions between sectors through demand and supply of consumption goods. ${ }^{(7)}$ It allows accounting for the heterogeneity in goods and services within sectors, for consequences of production bottlenecks, and substitution possibilities on the recovery of total output. ${ }^{(24)}$ See Appendix A for an overview of the most important modeling steps in the ARIO model, and Hallegatte ${ }^{(7,24)}$ for an extensive explanation of the model. A starting point for the ARIO model is the BE discussed in Section 2.4, which describes a disrupted and imbalanced economy directly after a disaster.

As the model is dependent on a large number of parameters, assumptions have to be made for the economic structure in the area under investigation. These assumptions are based on expert knowledge of the area ${ }^{(39)}$ and disaster modeling literature. ${ }^{(24,40)}$ First, due to the large variation in sectors in the port region of Rotterdam, we assume there is a high heterogeneity in goods and services between and within sectors. Second, we assume a full labor recovery of three months. Third, for the amount of inventory per sector, we differentiate between three different types of production modes: ${ }^{(40)}$ anticipatory, where production occurs in anticipation of future orders (e.g., agriculture and mining); responsive, where production takes places after receipt of customer orders (e.g., construction and services industries and most manufacturing industries); and just-in-time, where production takes place and goods are delivered as the order is placed (e.g., public utilities). For the anticipatory sectors, we assume an inventory stock of 90 days, for responsive sectors an inventory stock of 60 days, and for just-in-time sectors an inventory stock of 3 days. Other parameters settings are based on Hallegatte. ${ }^{(24)}$ See Table II for an overview of the "reference" parameter settings.

Direct flood damages to capital of both industries and households are added to the final demand in the I-O model, as we assume that the consequences of the flood result in additional demands of households and industries for goods and services in the retail and construction sectors. ${ }^{(7)}$ To model the recovery period, we use a time period of 10 years, where the model iterates over each day. In this way, production will be increasing gradually with each step, until the predisaster economic situation is reached again. At each step, the new production capacity is reassessed, taking into account the reduction in remaining damage and increase in labor, by means of the Cobb-Douglas function as defined in Section 2.2. For labor recovery, we assume a linear return to the predisaster values ${ }^{(8)}$ for each specific flood event, constrained by the maximum needed production capacity at a specific time period $t$ and per sector $j$ as shown in Equation (12), where $L_{j}^{p d}$ is the postdisaster labor, $L_{j}{ }^{0}$ is the initial amount of labor, and $\lambda$ is the recovery period for labor. A more elaborate explanation about the recovery period is found in Section 3.5.

$L_{j, t}=\min \left\{\left(L_{j}^{p d}+t * \frac{L_{j}^{0}-L_{j}^{p d}}{\lambda}\right) ;\left(L_{j, t-1} * \frac{X_{j, t}}{X_{j}^{0}}\right)\right\}$

For the determination of the remaining capital, we ascertain for each time period $t$ how much damage can be reduced. This is based on the remaining production capacity in the specific time period, as shown in Equation (13), where $K_{j, t}$ is the amount of capital per sector and $D^{d i r}$ the remaining flood damage per sector. 


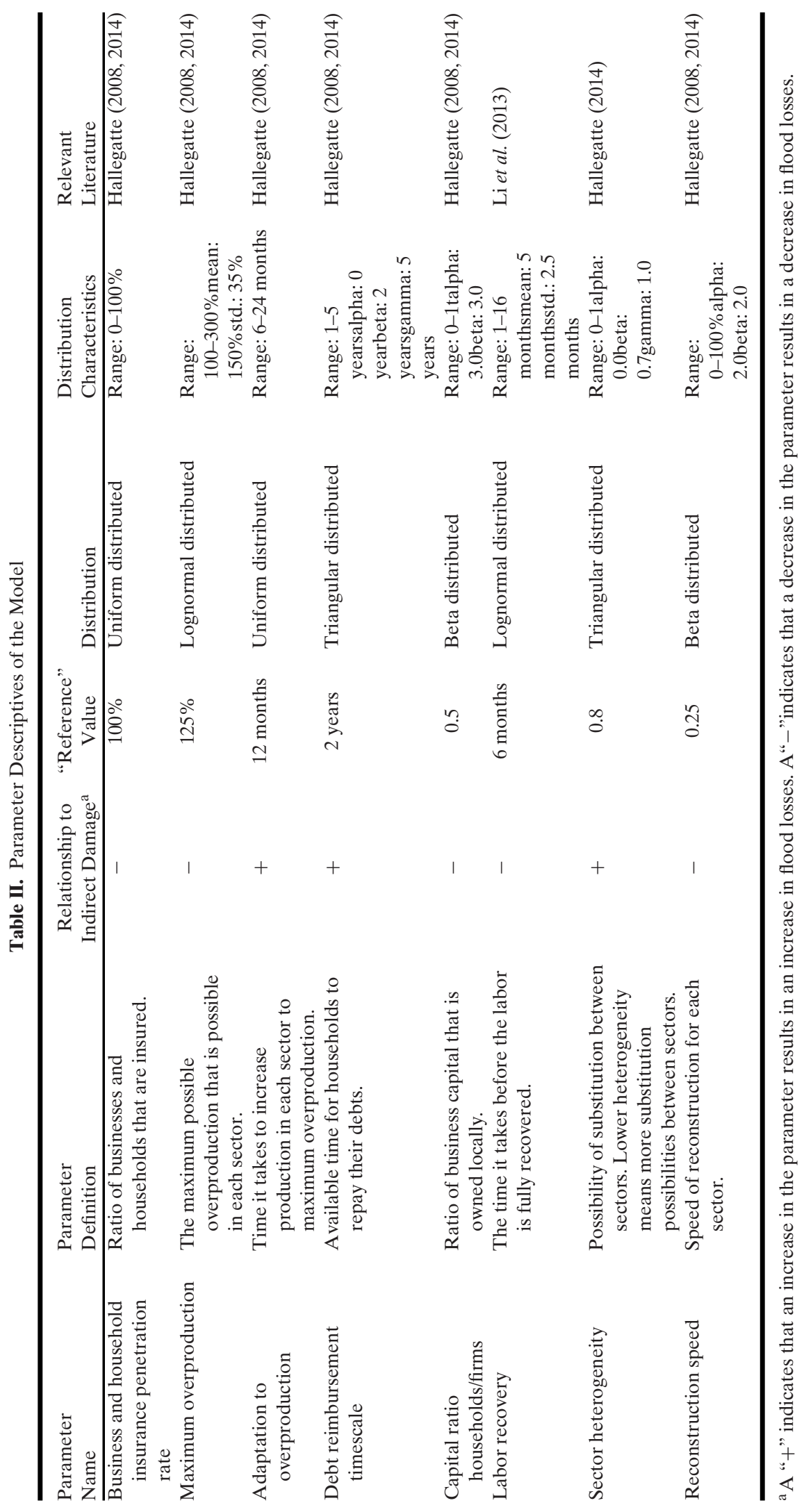




$$
K_{j, t}=K_{j, t-1}-\left(D_{j, t-1}^{d i r}-D_{j, t}^{d i r} \frac{X_{j, t}}{X_{j}^{0}}\right)
$$

The new obtained values for capital $\left(K_{j, t}\right)$ and labor $\left(L_{j, t}\right)$ at the beginning of each time period can be inserted into the Cobb-Douglas production function (Equation (3)) to yield the new maximum possible value added per sector. Finally, by using Equation (4), it is possible to define the new remaining production capacity $\left(X_{j, t}\right)$, and to recalculate the maximum production capacity per sector $\left(X_{j, t}{ }^{\max }\right)$ by using Equation (14), where " $s$ " is the economic shock per sector " $j$ " and " $\theta$ " is the maximum possible overproduction (see Table II).

$$
X_{j, t}^{\max }=X_{j}^{0}\left(1-s_{j, t}\right) \theta_{j, t}
$$

The remaining capital losses will reduce over each time period, and the total output produced will converge to the predisaster level. From this derivation, we can obtain the total indirect losses $\left(D^{\text {ind }}\right)$ by calculating the difference between the total value added throughout the recovery period, if no flood had occurred $\left(Y_{j}^{0}\right)$, and the total value added for each time period in the recovery period $\left(Y_{j, t}\right)$, as shown in Equation (15).

$$
D^{i n d}=\sum_{j=38}^{t} Y_{j}^{0}-\sum_{j=38}^{t} Y_{j, t}
$$

Finally, we can calculate the EAD of the specific direct losses (stock; see Section 2.1) and indirect losses (flow) for the case-study area. To derive the integral under the probability-loss curve, a trapezoid approach is taken to assess the EAD, as shown in Equation (16), where $f$ is the specific flood event, $P_{f}$ the probability for the flood event, and $D_{f}$ the losses for the flood event, which is either $D^{d i r}$ or $D^{\text {ind }}$ (important to note is that they should not be added up).

$$
\begin{aligned}
E A D= & \sum_{f=1 . .6}^{6}\left(\frac{\left(P_{f}-P_{f+1}\right) *\left(D_{f+1}-D_{f}\right)}{2}\right) \\
& +\left(P_{f}-P_{f+1}\right) * D_{i} .
\end{aligned}
$$

\section{UNCERTAINTY AND SENSITIVITY ANALYSIS SETUP}

Vast literature on modeling disaster consequences documents wide variation in model outcomes. ${ }^{(24,41,42)}$ These outcomes depend on the assumptions made by modelers (for example, with regard to accounting for direct loss or the path of recovery) and uncertainty in input parameters used in the modeling framework. Because damage estimates are often used as key figures in flood management decisions, it is important to explore the influence of model assumptions and parameter uncertainties on the resulting estimates. Therefore, the presented flood risk model will be used to carry out extensive $\mathrm{UA}$ and SA.

UA investigates the variation in model output as a result of imprecise knowledge of input parameters. $^{(43,44)}$ By performing analyses with different assumptions or parameter values, a range in output values is generated that represents the uncertainty in the output. SA is an extension to the UA, in which the variance in the output is attributed to the input parameters that were varied in the UA (Fig. 3). This shows how important uncertainty in each input parameter is in influencing the output. In this article, uncertainties and sensitivities are analyzed in two different ways. The first way is to investigate parameter uncertainty in the model using a global SA in which the entire sample space is systematically explored and interaction between input parameters can be accounted for. This contrasts local SA, which varies parameters one at a time. ${ }^{(45,46)}$ The second way is by exploring different recovery scenarios by adjusting critical assumptions in the modeling framework related to, among other factors, import and export restrictions and flood duration. This will illustrate the uncertainty related to model assumptions, which cannot be fully explored in the global SA, and unveils whether there are certain thresholds that mark structural changes in model outcomes.

\subsection{Uncertainty and Global SA}

By performing an SA, it is possible to identify both parameters that have a large effect on the model output and parameters that have little effect on the output. Parameters that have a large effect should receive additional attention in order to cope with the uncertainty they introduce, whereas parameters that have little effect are justified to keep constant. ${ }^{(47)}$ Since both UA and SA require a large number of repeated model evaluations, they will be carried out within a Monte Carlo modeling framework. Within this study, we follow the approach as described by Crosetto et al. ${ }^{(44)}$ and Helton ${ }^{(43)}$ to investigate the uncertainty and sensitivity related to input parameters. Those authors distinguish the following steps: (1) assigning distributions to input parameters, 


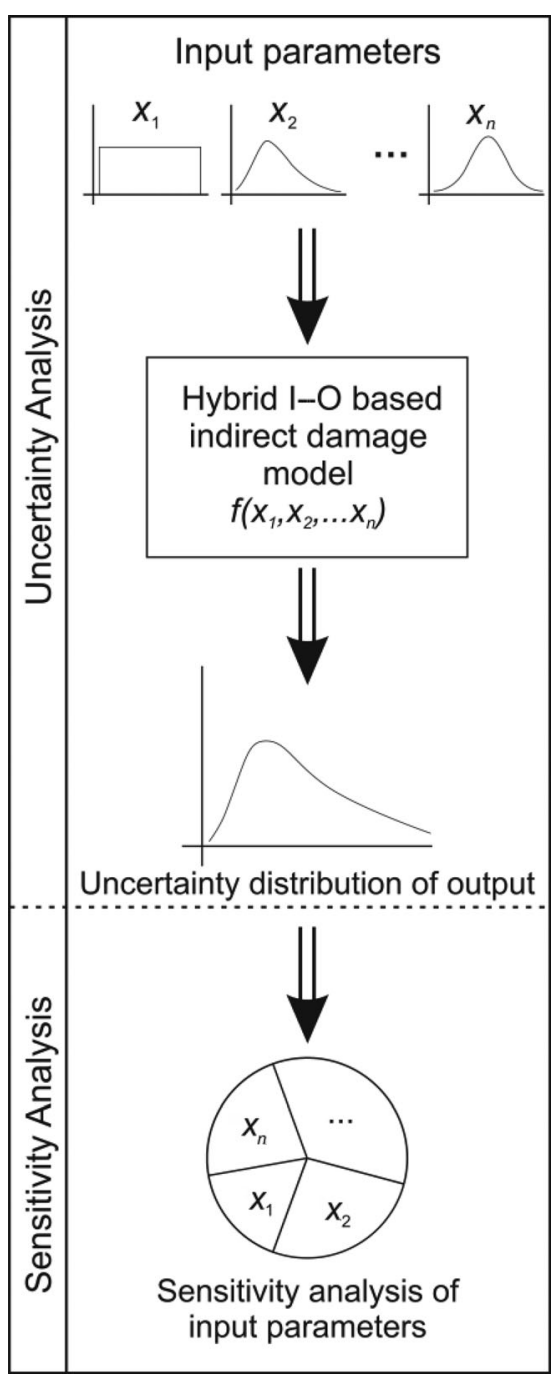

Fig. 3. Schematic representation of the uncertainty and sensitivity analyses (after Crosetto et al. ${ }^{(44)}$ ).

(2) generating samples of different combinations of input parameters, (3) evaluating the model using the generated combinations of input parameters, and (4) analyzing the results for uncertainty and sensitivity.

In this study, we will perform a global SA, which enables us to explore the variation in model output and to allocate the variation in this output to the different input parameters, taking into account interaction between these parameters. ${ }^{(47-49)}$ By applying the Simlab functions for Matlab, ${ }^{(50)}$ we sampled 2,816 different combinations of input parameters using the Sobol method. ${ }^{(51)}$ This method generates quasi-random samples of the parameters to be tested, covering the entire sample space (as opposed to varying one at a time). For the uncertainty and global SA, we look at the following parameters: business insurance penetration rate, household insurance penetration rate, maximum overproduction, adaptation to overproduction, debt reimbursement timescale, household/firm ratio capital ownership, labor recovery, sector heterogeneity, and reconstruction speed. See Table II for descriptions of these parameters and the distributions assigned to them.

\subsection{Scenario Approach}

Besides performing a global SA to investigate the effect of parameter uncertainty, we also explored in closer detail the effect of a couple of key modeling assumptions that cannot be explored in full detail within a global SA. This relates to assumptions in model structure that cannot be captured by a parameter, such as the availability of inventory, or to the exploration of parameters in such an extent that they would not be plausible for the case in question, but may be plausible in other cases (such as very long flood duration). In the global SA, the distribution of such parameters is assumed within more realistic boundaries for the case of Rotterdam. See below for an explanation of the assumptions addressed in the scenario approach.

- Restricted inventories in the construction and retail sector (Section 2.4). The ARIO model ${ }^{(24)}$ assumes that the inventories in the construction sector are unrestricted due to substitution possibilities and assistance from nonaffected regions. Practice shows that this is not always the case and rigidities occur often at the beginning of recovery. Therefore, we will explore to what extent indirect losses will change when the construction and retail sectors have limited inventory, similar to the other sectors in the affected region.

- Variation in flood duration. As mentioned in Section 2.4, the time of flood duration can have a significant influence on the output of the model. If an area is inundated for a couple of months (as can be expected in polder areas), during that time production is halted and recovery is delayed, substantially influencing the indirect losses. For unprotected outer dike areas, such as in our study, it is assumed that the water flows quickly away; ${ }^{(37)}$ however, in the face of generality offered by the model we shall analyze how differences in flood duration can affect the 
model output also within protected dike-ring areas.

- Time of labor recovery (Section 2.4). Due to a lack of empirical data on recovery periods in port areas, it is not known how much time it takes for labor to recover. Numerous factors can have an influence, all covered within uncertainty (e.g., duration of evacuation, speed at which the flooded area becomes accessible, speed of recovery of utilities, infrastructure, and transportation). For the Rotterdam area, we assume a relatively quick labor recovery, also in the global SA. Again, for the sake of general applicability, it is worthwhile to check extreme durations of labor recovery.

- Availability of inventories present after the flood and the time of restoration of these inventories (Section 2.4). Literature ${ }^{(24)}$ shows that this can significantly change the flood losses and a near absence of inventories can even make the economy collapse. Therefore, it is important to test whether similar effects are to be expected in different areas and for different flood severity levels.

\section{DATA AND STUDY AREA}

The case-study area concerns the municipality of Rotterdam in the Netherlands, with one of the largest seaports in the world, and the surrounding municipalities. Besides a large industrial zone, the area mainly consists of built environment (both commercial and residential), agricultural land, and small patches of nature (Fig. 4). Most of the harbor area is unprotected and located outside the flood embankments, which makes it more vulnerable to floods.

As mentioned in Section 2, the modeling framework proposed in this article only requires three data inputs: an inundation map, a land-use map, and an I-O table, making it widely applicable. The inundation maps in this study are based on maps developed by Huizinga, ${ }^{(52)}$ with flood return periods ranging between $1 / 10$ and 1/10,000. In the harbor area, we assume the water flows away within one day for high-probability floods and up to one week for a lowprobability flood. The land-use map is an updated version of the land-use map developed by De Moel et al. ${ }^{(25)}$ and includes 16 industrial land-use classes.

For the indirect loss assessment, an I-O table is required. For illustrative purposes, we make use of an I-O table for the year 1992, developed by IRIOS $^{(53)}$ and corrected for inflation. Even though these data are not recent, they allow us to test the modeling framework. As found in Nijdam et al., ${ }^{(54)}$ the relative industrial shares in the port have remained similar over time, which suggests that the industrial dependencies of the 1992 table are still relevant for the current port activities. However, the total
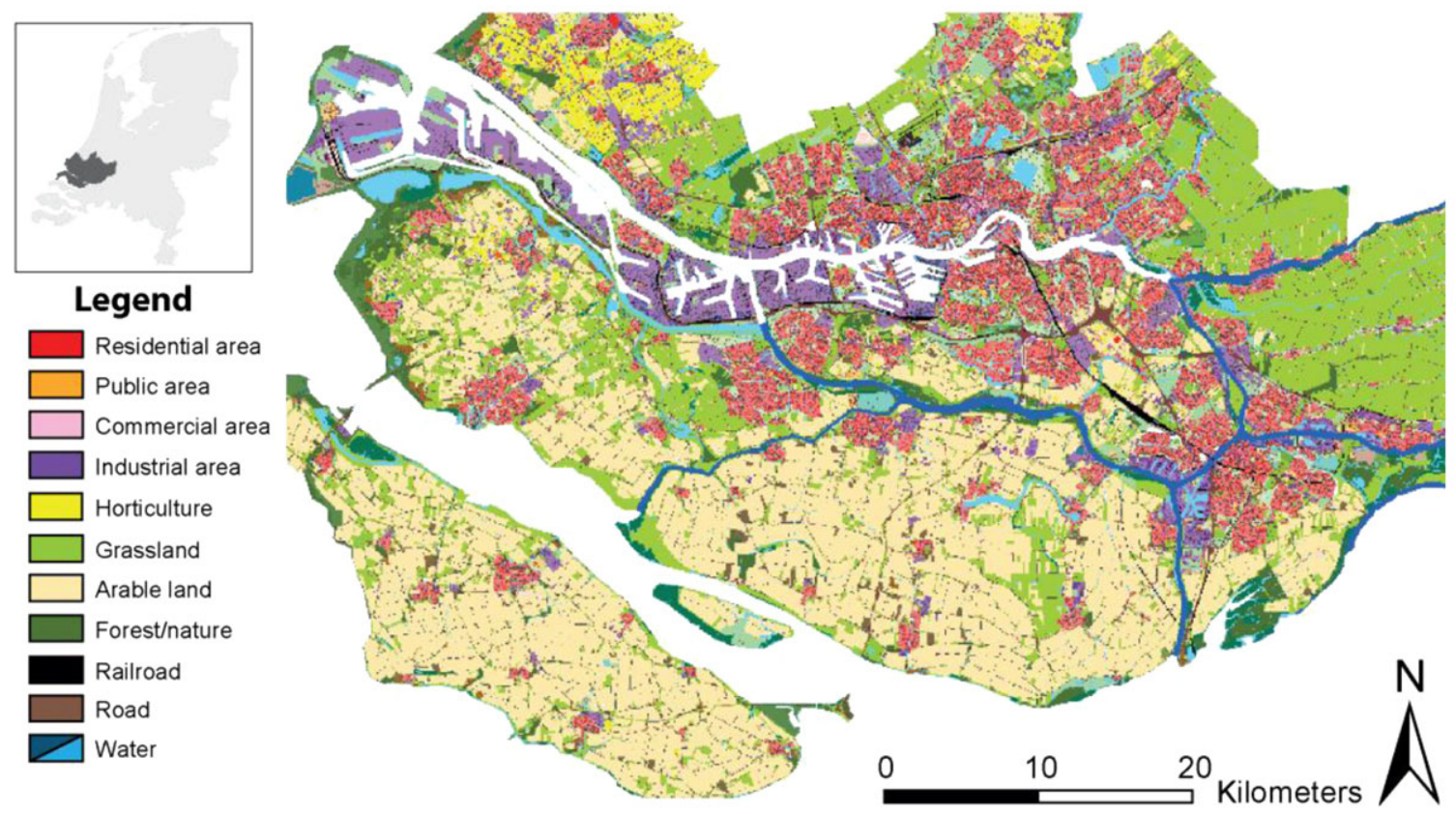

Fig. 4. Land-use map of the greater Rotterdam area. 
Table III. Flood Loss and Risk Estimates for the Rotterdam Area

\begin{tabular}{lccc}
\hline $\begin{array}{l}\text { Return } \\
\text { Period }\end{array}$ & $\begin{array}{c}\text { Direct Losses } \\
\text { (in Billion Euros) }\end{array}$ & $\begin{array}{c}\text { Indirect Losses } \\
\text { (in Billion Euros) }\end{array}$ & $\begin{array}{c}\text { At 99\% of Initial } \\
\text { Total Output }\end{array}$ \\
\hline $1 / 10$ & 0.22 & 0.13 & 18 days \\
$1 / 100$ & 0.44 & 0.29 & 78 days \\
$1 / 1,000$ & 0.76 & 0.61 & 173 days \\
$1 / 2,000$ & 0.92 & 0.83 & 255 days \\
$1 / 4,000$ & 1.10 & 1.14 & 351 days \\
$1 / 10,000$ & 1.88 & 2.51 & 647 days \\
EAD (million Euro/year) & $\mathbf{3 6 . 1}$ & $\mathbf{2 3 . 4}$ & \\
\hline
\end{tabular}

losses might be possibly underestimated due to the large growth of value added in the Rotterdam port area since 1992. ${ }^{(39)}$ See the Appendix for a list of sectors that are included in this table.

\section{RESULTS AND DISCUSSION}

\subsection{Flood Risk Estimates}

For the harbor area of Rotterdam, we assessed the flood damage for six flood events with varying flood probabilities (Table III). For high-probability floods, we see that direct losses are almost two times higher than the indirect losses ( 0.22 billion Euro damage for direct losses vs. 0.13 billion Euro damage for indirect losses). However, as soon as the flood becomes less probable and more severe, the indirect losses start to become much more important (up to $40 \%$ higher than the direct losses for the $1 / 10,000$ flood). From floods with a return period of 1/4,000 and higher, we find that the indirect losses are larger than the direct losses. This difference can be explained by the expected relative quick recovery with high-probability floods, which prevents large income losses within the affected area as well as elsewhere in the economy. At the same time, lowprobability floods are more severe due to higher water depths, longer flood durations, and a larger flood extent, thus leaving many more businesses directly affected. Besides, because a larger share of sectors is out of business, income that is lost over a longer period of time and a longer recovery period result in high indirect losses in the rest of an economy, and therefore high indirect losses for this type of floods. When combining the losses for different return periods into EAD (Equation (16)) we see that the direct risk still remains larger than the indirect risk (approximately $50 \%$ larger). When disaggregating the direct losses for the $1 / 10,000$ flood, the largest share in damages can be found in the retail sector $(35 \%)$, the oil sector $(17 \%)$, and in residential areas $(10 \%)$.

Fig. 5 shows the total output of the whole region in the postdisaster period for each time period. As can be seen, when the flood hits the area, the economy is not at its lowest point. The most important reason for this phenomenon is the fact that most of the firms still have inventories available. As soon as all the firms run out of stock, the economy hits the lowest point. Directly thereafter, however, we see a rather quick recovery in the first couple of months. The main reason is the recovery of labor, which is assumed to last for a maximum three months (this is assumed for all return periods). After labor is recovered, it is mostly capital that needs to be reconstructed. As seen in Table III, for highprobability floods where the damages are low and relatively little capital is lost, recovery to the predisaster situation is quick (several weeks to several months).

\subsection{Parameter Uncertainty and Sensitivity}

The results for the uncertainty and global SA are shown in Table IV and Fig. 6. Table IV shows mean and median values for each of the six return periods and the $2.5 \%$ and $97.5 \%$ percentiles to illustrate the uncertainty in the model output. We do not report the standard deviations here due to the non-Gaussian distribution of the model output. In addition, the median damage is a more appropriate centrality indicator in this case compared to the arithmetic mean. ${ }^{(47)}$ Overall, the $95 \%$ confidence interval and the histograms in Fig. 5 show that the uncertainty and variation in model output is substantial. Interestingly, we see large differences in model output uncertainty between the different return periods. For the 1/100 flood, the confidence interval 
Table IV. Statistics of the Model Output for Each Flood Event in This Study

\begin{tabular}{lccccccc}
\hline & \multicolumn{5}{c}{ Flood Return Period (Model Output in Billions) } \\
\cline { 2 - 6 } & $1 / 10$ & $1 / 100$ & $1 / 1,000$ & $1 / 2,000$ & $1 / 4,000$ & $1 / 10,000$ & EAD (million Euro/year) \\
\hline Mean indirect losses (Euro) & 0.13 & 0.25 & 0.50 & 0.64 & 0.85 & 2.53 & $\mathbf{2 1 . 0}$ \\
Median indirect losses (Euro) & 0.13 & 0.24 & 0.48 & 0.61 & 0.79 & 1.88 & $\mathbf{2 0 . 2}$ \\
2.5\% percentile (Euro) & 0.05 & 0.10 & 0.23 & 0.29 & 0.40 & 1.05 & $\mathbf{8 . 9}$ \\
$97.5 \%$ percentile (Euro) & 0.22 & 0.41 & 0.77 & 0.99 & 1.52 & 7.28 & $\mathbf{3 5 . 0}$ \\
Indirect losses using "reference" values & 0.13 & 0.29 & 0.61 & 0.83 & 1.14 & 2.51 & $\mathbf{2 3 . 4}$ \\
\hline
\end{tabular}

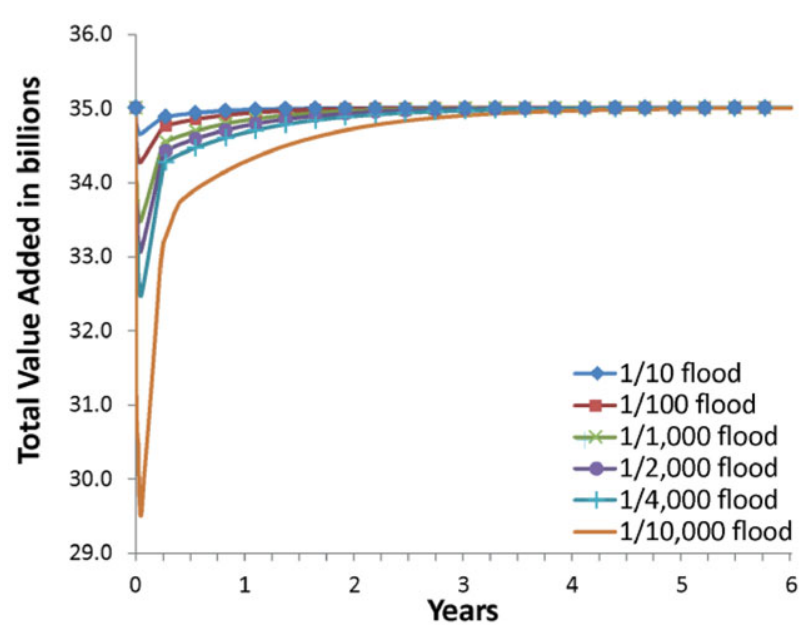

Fig. 5. Total value added per time period in the postdisaster period for the total regional economy.

shows that the value of indirect losses at the $97.5 \%$ percentile is 1.7 times higher than the median indirect losses. However, for the $1 / 10,000$ flood, the indirect losses at the 97.5 percentile are almost four times higher than the median indirect losses. The EAD resembles results similar to the high-probability floods because these contribute the most losses to EAD in absolute terms compared to low-frequency floods. ${ }^{(55)}$ For all return periods, the indirect losses using "reference values" (see Table II) are somewhat higher compared to the median indirect losses.

The histograms in Fig. 6 visualize the variation in model output for three different inundation scenarios. The panel on the left shows the histogram of a $1 / 100$ flood, which is much more normally distributed than the panel on the right (a 1/10,000 flood), which is particularly right-skewed and has a long tail going into higher indirect losses. These outcomes imply that the different model parameters have different influences across different severities of floods. This becomes evident from the diagrams in Fig. 7. For the 1/100 flood, the speed of reconstruction exerts the highest influence on the model output (the green part; colors visible in online version), followed by the heterogeneity of the economy (the orange part). For the 1/1,000 flood, this is just the other way round (i.e., heterogeneity of the economy now has the highest influence). For both floods, labor recovery (the blue part) has the third highest influence, albeit much smaller than the other two. The 1/10,000 flood shows a slightly different pattern. Again, the heterogeneity of the economy and the speed of recovery have a large influence, but also the household to firm capital ownership ratio (the purple part) now shows a significant influence on the model output. This implies that for large-scale floods, damage estimates may vary substantially depending on whether predominantly local, privately owned businesses are hit by the flood, or large businesses that are less dependent on the regional economy.

Overall, the model output is quite sensitive to assumed levels of parameters, particularly to the heterogeneity of the economy. This is in line with results of Hallegatte. ${ }^{(7,24)}$ However, in contrast to Hallegatte, ${ }^{(7,24)}$ the parameters related to maximum overproduction, and adaptation to overproduction, have relatively little influence on the results compared to the other parameters. However, we found a reduction of $7 \%$ in the estimated losses when increasing the maximum overproduction from $125 \%$ (the reference value) to $200 \%$. This implies that the overproduction does influence the loss estimates (although less so), as also found in studies in, for instance, New Orleans, ${ }^{(7,24)}$ Copenhagen, ${ }^{(56)}$ and Mumbai. ${ }^{(57)}$

\subsection{Flood and Recovery Scenarios}

For the scenario approach, we tested differences in labor recovery period, flood duration, unrestricted stock availability in the construction and retail sector, 

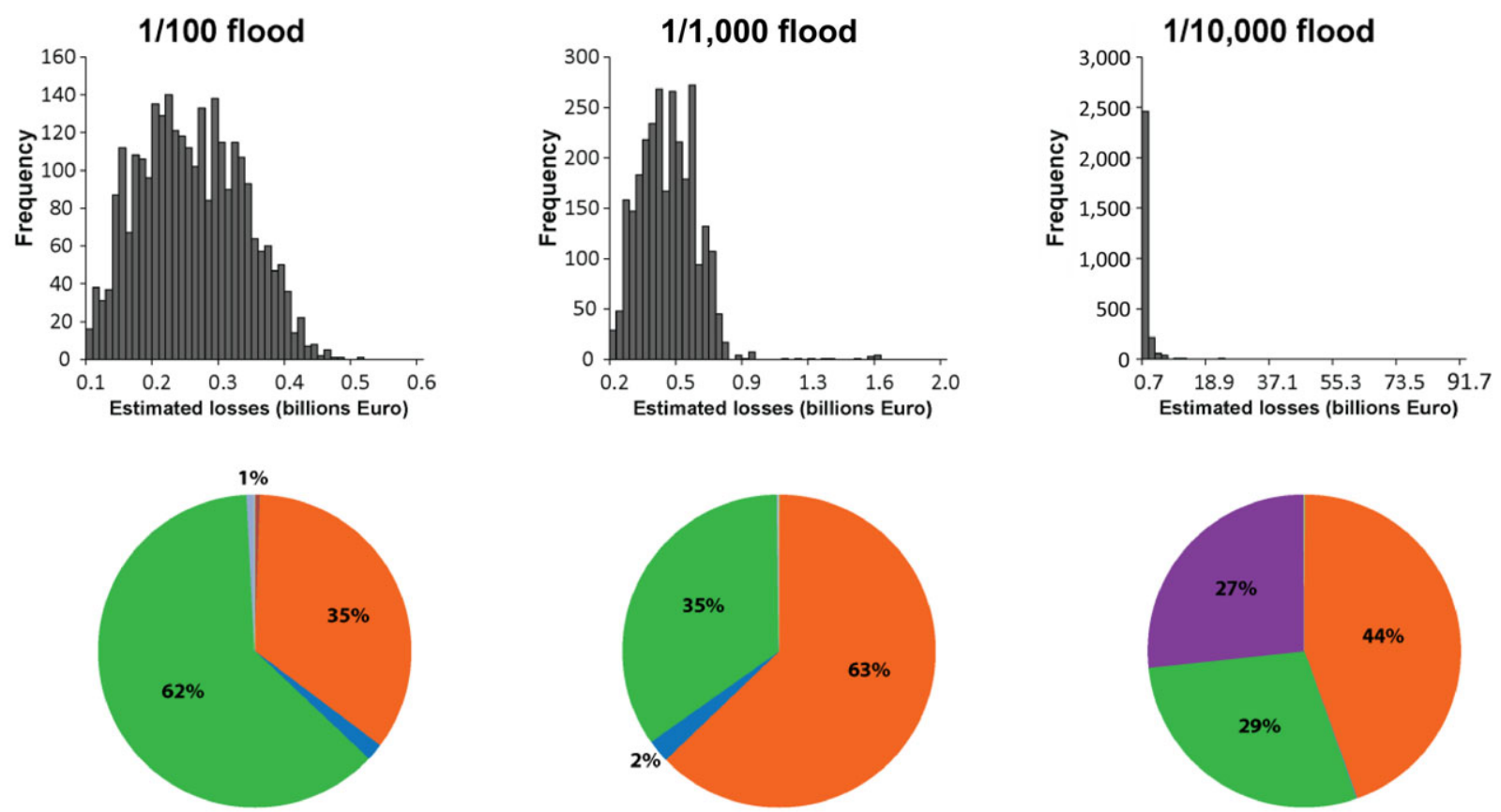

\begin{tabular}{|c|c|}
\hline Business insurance penetration rate & - Household insurance penetration rate $\| \mathrm{N}$ \\
\hline $\begin{array}{l}\text { Heterogeneity } \\
\text { Household/firms ratio capital ownersh }\end{array}$ & $\begin{array}{l}\text {-Speed of reconstruction } \\
\text { Reimbursment rate }\end{array}$ \\
\hline
\end{tabular}

Fig. 6. Results of the uncertainty (histograms) and sensitivity (pie charts) analyses for the 1/100,1/1,000, and 1/10,000 floods. The histograms show the variation in the damage estimates resulting from the Monte Carlo analyses. Note that a different scale is used for the $x$-and $y$-axis between the different floods. The pie charts represent the total variance of the output and indicate how much the uncertainty in each of the input parameters contributes to the variance of the damage estimates.

and the inventories available per sector. We found that there is only a small (less than $2 \%$ ) reduction in EAD if we assume that the available stocks in the construction and retail sector are unconstrained. This implies that in the Rotterdam region, the construction and retail sector are already big enough to be able to satisfy all additional demand due to reconstruction. For the other tested assumptions, we will describe the results only for the 1/10,000 flood as the indirect effects are most substantial there (see Fig. 5).

Fig. 7 shows the different model outputs when varying labor recovery and flood duration. The left-hand panel of Fig. 7 shows the postdisaster period for different labor recovery periods for the $1 / 10,000$ flood, where up to 12 months there are no considerable changes in the recovery path. However, if labor recovery takes up to 24 months, the recovery takes much longer and the losses almost quadruple compared to a labor recovery period of three months (2.52 billion Euro losses for three months of labor recovery vs. 10 billion Euro losses for 24 months of labor recovery). It is important to note that capital and labor have different recovery paths and might therefore both return at different time periods at their predisaster values (in this model, labor always returns more quickly to its predisaster value than capital). However, when labor is back at its predisaster value, this does not mean that it can directly be fully utilized without the full amount of capital. In such a situation, the Cobb-Douglas function would overestimate total production. Essentially, the CobbDouglas function "smoothens" predicted production growth during recovery (over the top of the "steps"), which rather takes place stepwise. Therefore, estimated production may deviate from "real" output at some intermediate stages of recovery, but would expectedly approximate real production when all production factors are available. Even though this smoothing might influence the final estimation of losses, it is expected this influence is rather small and should not influence the composition of the losses nor the EAD, which is mainly influenced by the small-scale floods. 

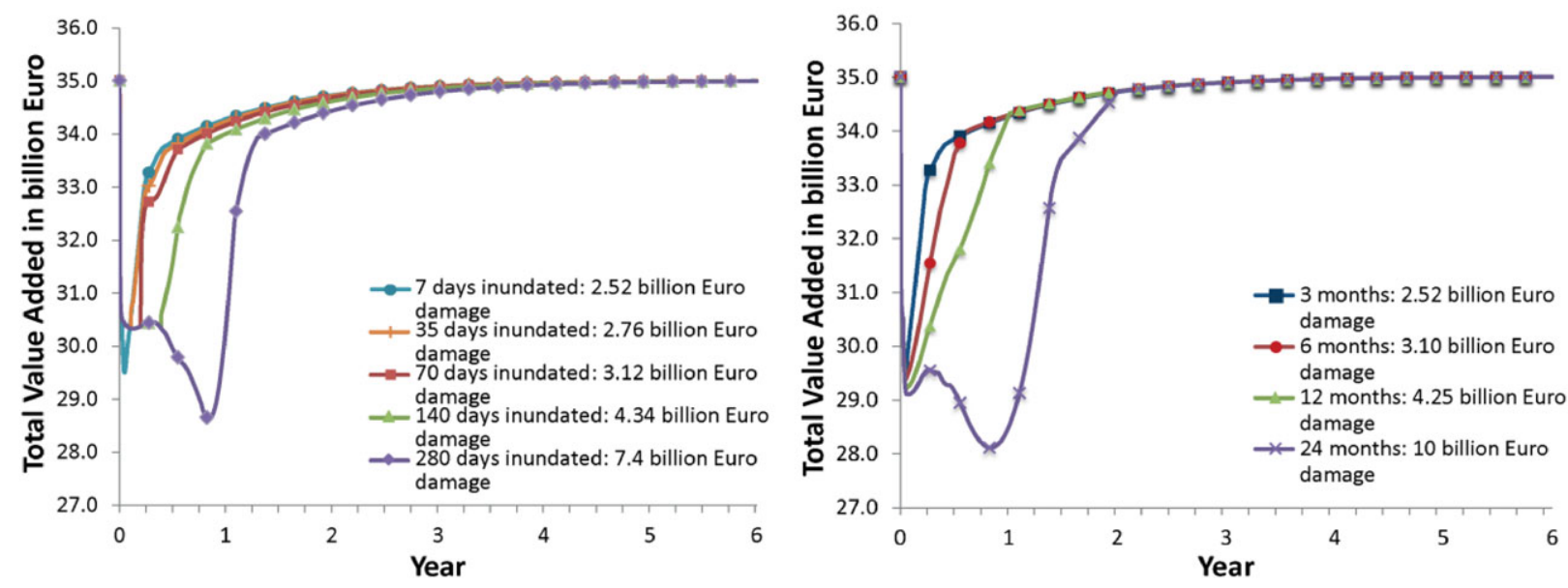

Fig. 7. Recovery paths for the "flood duration" (left panel) and "labor recovery" (right panel) parameters for a 1/10,000 flood. The total flood damage for each scenario is shown in the legend of the graph.

Similar indirect losses are found for the flood duration (right-hand panel of Fig. 7). Up to 140 days of no recovery, the recovery path stays relative similar. However, when the area is inundated for up to 280 days, we find a significant increase in losses (losses triple). Flood duration can thus be an important factor impacting (indirect) flood losses, as also found by Dutta et al. ${ }^{(58)}$ and Förster et al. ${ }^{(59)}$ Both results imply that from a certain threshold in flood impact, the regional economy has severe problems in getting back to its predisaster state. However, it is important to note that for the labor recovery and flood duration, respectively, 24 months and 280 days are extreme cases and are expected to be rare occurrences. Nonetheless, it shows how vulnerable an economy can be when extreme events occur.

Lastly, our analyses confirm the findings of Hallegatte ${ }^{(24)}$ that the amount of available postdisaster inventory highly influences the losses. When we reduce the inventories of all sectors by $50 \%$ and assume also an inventory restoration that takes twice as long as in the baseline case, the indirect losses for the $1 / 10,000$ flood double. It is important to note that this increase is only visible for the $1 / 10,000$ flood. For the higher probability floods, almost no differences occur. This implies that the size of inventories only matters for a particularly severe and spatially extensive flood. On the other hand, when we double the postdisaster inventory of each sector, the indirect losses for the $1 / 10,000$ flood decrease by only $8 \%$. This suggests that there might be an optimum value of stock available, which may have important implications for disaster preparedness measures. Finally, reducing the available inventories by more than $50 \%$, the indirect losses increase exponentially (up to 10 times). Sectors running out of inventories and thus unable to supply their products therefore impose limitations on production possibilities of other sectors throughout the economy. This can eventually result in a full production standstill, leading to economic collapse. ${ }^{(24)}$

\section{CONCLUSIONS}

In this study, we have introduced and successfully applied a dynamically coupled direct and indirect risk model for small- and large-scale flood events that allows modeling of total economic losses from the flood hazard, up to a full recovery. The concept of EAD, borrowed from engineering literature, was thereby applied to reflect the expected losses from various types of floods. One of the novelties of this approach is the use of a Cobb-Douglas production function that translates losses in both capital and labor into production losses, making loss accounting more consistent. Such an approach is of particular importance for the large (low-probability) floods that involve human victims. Furthermore, the model allows for conducting an extensive SA of its underlying assumptions and identifying those parameters for which model outcomes are highly sensitive. For other parameters, "safe" ranges are suggested within which models estimates remain stable.

This study showed the added value of combining different flood loss estimation approaches into a single dynamic integrative framework. By applying six flood events $(1 / 10$ up to $1 / 10,000)$ to reflect the full risk distribution, estimates of the consequences of both high- and low-probability floods, as well as 
differences therein, can be obtained. Improved insight into the composition of losses obtained with the help of the proposed model can thus help make better decisions with regard to, for instance, flood protection measures.

We can draw two important conclusions from our results for disaster modelers and practitioners. A first conclusion is that small (high-probability) events are qualitatively different from large (lowprobability) events in terms of the ratio direct/indirect damages to an economic system. Our results showed that for high-probability floods (up to $1 / 4,000$ per year) direct losses remain larger compared to the indirect losses, but for low-probability floods (less frequent than $1 / 4,000$ per year), the indirect losses are more substantial relative to the direct losses. In terms of EAD, the direct risk still remains larger than the indirect flood risk (approximately $50 \%$ larger). However, looking at the EAD alone can be misleading. Our results show that different parameters exert a different influence on loss estimates for the high-probability and low-probability floods. As the EAD is mainly influenced by outcomes of highprobability floods, care should be taken in drawing conclusions about an "average" effect of a particular parameter. This implies that both the EAD and its composition need to be considered when assessing flood risk for a specific region and making policy choices.

A second important conclusion of our findings is that there are parameter thresholds that distinguish small (high-probability) events from large (low-probability) events in terms of resulting damages to the entire economic system. The UA and SA show that there is large variety in parameter values that makes model outcome extremely sensitive (upper-bound estimates are up to seven times higher than lower-bound estimates). Interestingly, large differences in parameter influence are found between high-probability and low-probability floods. For instance, the speed of labor recovery is of high influence for high-probability floods, whereas the heterogeneity of the economy determines for a large part the amount of indirect losses for low-probability floods.

Our results therefore imply that making appropriate assumptions about parameter values based on prevailing geographic conditions and type of flood event is critical to model outcomes. We find that some parameters appear to be of particular importance in this context. In particular, if "labor recovery period" or "the flood duration" become too long (two years for labor; half a year for the flood duration) our results show that the indirect losses triple compared to the reference situation. While these identified thresholds for the labor recovery and flood duration are rather extreme, our analyses show how vulnerable an economy can be when extreme events occur. In addition, when reducing available stocks by more than $50 \%$, the indirect losses increase up to 10 times in low-probability floods. These results imply that maintaining an inventory to allow a certain degree of flexibility in the production chain should be an important focus in disaster preparedness and recovery planning. It is important that businesses in flood-prone areas can maintain and quickly restore their inventories to speed up the recovery process.

Despite uncertainties, our results give an indication of the total consequences of a flood when taking both direct and indirect losses into account. In the future, more research is required on a number of elements of this model. For instance, we have assumed here a return to the predisaster production proportions and ultimately predisaster production capacities, which may not necessarily be targeted or even be possible in a postdisaster situation. Future research may therefore explore other recovery trajectories. Also, substitution effects outside the region can play a significant role in the speed of recovery. Thus, an interregional model would be more appropriate in order to capture the indirect effects after a flood as well as identify sources for recovery available within an economy. Finally, one can assume that affected critical infrastructure, which may cause, among others, power outages, shortages in fresh water, or disruption of communication channels, can significantly slow down the recovery process, deserves additional attention in disaster modeling.

\section{ACKNOWLEDGMENTS}

We are grateful to Wouter Botzen for his comments and suggestions to improve earlier drafts of this article, Stéphane Hallegatte for providing the ARIO model, and the Simlab group for providing the statistical framework that was used in this study. We would also like to thank the editors and three anonymous reviewers for their constructive comments. This research was carried out and funded as part of the EU FP7 TURAS project (Grant Agreement No: 282834), the ENHANCE project (Grant Agreement No: 308438), and "Knowledge for Climate" (Theme 6-Climate Proof Flood Risk Management) (http://www.climateresearchnetherlands.nl). 


\section{APPENDIX A: FRAMEWORK ARIO MODEL}



Fig. A1. Modeling framework of the most important steps within the ARIO model.

\section{APPENDIX B: LIST OF INDUSTRIAL SECTORS}

Table B.I. List of Economic Sectors in the Input-Output Table

\begin{tabular}{ll}
\hline 1 & Agriculture, horticulture, and forestry \\
2 & Fishing \\
3 & Mining and quarrying \\
4 & Manufacture of dairy products \\
5 & Manufacture of other food products \\
6 & Beverage and tobacco industry \\
7 & Textiles industry \\
8 & Clothing industry \\
9 & Leather, footwear, and other leatherwear \\
10 & Wood and furniture industry (excluding metal furniture) \\
11 & Paper, cardboard, and paperware industry \\
12 & Printing, publishing, and related industries \\
13 & Petroleum industry \\
14 & Chemical, rubber, and plastic-processing industry \\
15 & Building materials, earthenware, and glass products \\
16 & Basic metal industry, manufacture of metal products, and \\
& machinery \\
17 & Electro technical industry \\
18 & Automobile industry \\
\hline
\end{tabular}

Table B.I. Continued

19

20

21

21

22

23

24

25

26

27

28

29

30

31

32

33

34

35

36

37

38
Manufacture of other transport equipment Instruments, optical goods, and other industry Public utilities

Construction and installation of construction projects Wholesale trade, trade intermediaries, and retail trade Hotels, restaurant, cafés, etc.

Repair of consumer goods

Sea and air transport

Road transport and supporting industries for transport Communication

Banking

Insurance

Exploitation of and trade in real estate

Business services, renting machinery, other movables Government, compulsory social security, and defense

State and nonstate subsidized education

Social services

Health and veterinary services

Cultural, sports, and recreational services Other services 


\section{REFERENCES}

1. Kok M, Huizinga HJ, Vrouwenvelder A, Barendregt A. Standaardmethode 2004-Schade En Slachtoffers Als Gevolg van Overstromingen, RWS Dienst Weg-En Waterbouwkunde, 2005.

2. Thieken AH, Olschewski A, Kreibich H, Kobsch S, Merz B. Development and evaluation of FLEMOps-A new flood loss estimation model for the private sector. Pp. 315-324 in 1st International Conference on Flood Recovery, Innovation and Response (FRIAR), July 2-3, London, UK, 2008.

3. Penning-Rowsell E, Viavattene C, Pardoe J, Chatterton J, Parker D, Morris J. The Benefits of Flood and Coastal Risk Management: A Handbook of Assessment Techniques. London: Middlesex University Press, 2010.

4. Kreibich H, Seifert I, Merz B, Thieken AH. Development of FLEMOcs-A new model for the estimation of flood losses in the commercial sector. Hydrological Sciences Journal, 2010; 55(8):1302-1314

5. Rose A, Liao S-Y. Modeling regional economic resilience to disasters: A computable general equilibrium analysis of water service disruptions. Journal of Regional Science, 2005; 45(1):75-112.

6. Steenge AE, Bočkarjova M. Thinking about imbalances in post-catastrophe economies: An input-output based proposition. Economic Systems Research, 2007; 19(2):205-223.

7. Hallegatte S. An adaptive regional input-output model and its application to the assessment of the economic cost of Katrina. Risk Analysis, 2008; 28(3):779-799.

8. Li J, Crawford-Brown D, Syddall M, Guan D. Modeling imbalanced economic recovery following a natural disaster using input-output analysis. Risk Analysis, 2013; 33(10):1908-1923.

9. Jonkeren O, Giannopoulos G. Analysing critical infrastructure failure with a resilience inoperability input-output model. Economic Systems Research, 2014; 26(1):39-59.

10. Jonkman SN, Bočkarjova M, Kok M, Bernardini P. Integrated hydrodynamic and economic modelling of flood damage in the Netherlands. Ecological Economics, 2008; 66(1):77-90.

11. FEMA. HAZUS-MH MR4 Flood Model Technical Manual. Washington, DC: Federal Emergency Management Agency, Mitigation Division, 2009.

12. Klijn F, van Buuren M, van Rooij SAM. Flood-risk management strategies for an uncertain future: Living with Rhine river floods in the Netherlands? Ambio, 2004; 33(3):141-147.

13. Samuels P, Klijn F, Dijkman J. An analysis of the current practice of policies on river flood risk management in different countries. Irrigation and Drainage, 2006; 150(May 2005):2527.

14. Grossi P, Kunreuther H. Catastrophe Modeling: A New Approach to Managing Risk. Springer, 2005.

15. Okuyama Y. Disaster and economic structural change: Case study on the 1995 Kobe earthquake. Economic Systems Research, 2014; 26(1):98-117.

16. Rose A. Economic principles, issues, and research priorities in hazard loss estimation. Pp. 13-36 in Modeling Spatial and Economic Impacts of Disasters. Berlin/Heidelberg: Springer, 2004.

17. Okuyama Y. Economics of natural disasters: A critical review. Research Paper, 2003; 12:20-22.

18. Bočkarjova M, Steenge AE, Hoekstra AY. Management of flood catastrophes: An emerging paradigm shift. Pp. 70-90 in Reinhard S, Folmer H (eds). Water Policies in the Netherlands: Integrated Management in a Densely Populated Delta. Resources for the Future. Washington, DC: World Bank, 2009.

19. Jongman B, Kreibich H, Apel H, Barredo JI, Bates PD, Feyen L, Gericke A, Neal J, Aerts JCJH, Ward PJ. Comparative flood damage model assessment: Towards a European approach. Natural Hazards and Earth System Science, 2012; 12(12):3733-3752.

20. Okuyama Y, Santos JR. Disaster impact and input-output analysis. Economic Systems Research, 2014; 26(1):1-12.

21. Okuyama Y, Hewings GJD, Sonis M. Measuring economic impacts of disasters: Interregional input-output analysis using sequential interindustry model. Pp. 77-101 in Okuyama Y, Chang SE (eds). Modeling Spatial and Economic Impacts of Disasters. New York: Springer, 2004.

22. Rose A, Wei D. Estimating the economic consequences of a port shutdown: The special role of resilience. Economic Systems Research, 2013; 25(2):212-232.

23. Bočkarjova M. Major disasters in modern economies: An input-output based approach at modelling imbalances and disproportions. PhD Dissertation, University of Twente, 2007.

24. Hallegatte S. Modeling the role of inventories and heterogeneity in the assessment of the economic costs of natural disasters. Risk Analysis, 2014; 34(1):152-167.

25. De Moel H, Vliet M, Aerts JCJH. Evaluating the effect of flood damage-reducing measures: A case study of the unembanked area of Rotterdam, the Netherlands. Regional Environmental Change, 2014; 14(3):895-908.

26. Smith DI. Flood damage estimation-A review of urban stage-damage curves and loss functions. Water S.A., 1994; 20(3):231-238.

27. Tebodin. Schade bij inundatie van buitendijkse industrie, 1998.

28. Tebodin. Schadecurves industrie ten gevolge van overstroming, 2000.

29. Cobb CW, Douglas PH. A theory of production. American Economic Review, 1928:139-165.

30. Hallegatte S, Hourcade J-C, Dumas P. Why economic dynamics matter in assessing climate change damages: Illustration on extreme events. Ecological Economics, 2007; 62(2):330-340.

31. Hosoe N, Gasawa K, Hashimoto H. Textbook of Computable General Equilibrium Modeling: Programming and Simulations. Palgrave Macmillan, 2010.

32. Solow RM. A contribution to the theory of economic growth. Quarterly Journal of Economics, 1956; 70(1):65-94.

33. Barker K, Santos JR. Measuring the efficacy of inventory with a dynamic input-output model. International Journal of Production Economics, 2010; 126(1):130-143.

34. Santos JR, Haimes YY. Modeling the demand reduction input-output (I-O) inoperability due to terrorism of interconnected infrastructures. Risk Analysis, 2004; 24(6):14371451.

35. Santos JR, May L, Haimar A El. Risk-based input-output analysis of influenza epidemic consequences on interdependent workforce sectors. Risk Analysis, 2013; 33(9):1620-1635.

36. Barker K, Santos JR. A risk-based approach for identifying key economic and infrastructure systems. Risk Analysis, 2010; 30(6):962-974.

37. Wagenaar D. The significance of flood duration for flood damage assessment. Masters Dissertation, 2012.

38. Leontief WW. Input-output economics. Scientific American, 1951; 185(4):15-21.

39. Merk O, Notteboom T. The competitiveness of global portcities: The case of Rotterdam, Amsterdam - The Netherlands. OECD Regional Development Working Papers, 2013/08, 2013.

40. Okuyama Y. Modeling spatial economic impacts of an earthquake: Input-output approaches. Disaster Prevention and Management, 2004; 13(4):297-306.

41. Koks EE, De Moel H, Aerts JCJH, Bouwer LM. Effect of spatial adaptation measures on flood risk: Study of coastal floods in Belgium. Regional Environmental Change, 2014; 14(1):413-425. 
42. De Moel H, Aerts JCJH. Effect of uncertainty in land use, damage models and inundation depth on flood damage estimates. Natural Hazards, 2011; 58(1):407-425.

43. Helton JC. Uncertainty and sensitivity analysis techniques for use in performance assessment for radioactive waste disposal. Reliability Engineering \& System Safety, 1993; 42(2):327367.

44. Crosetto M, Tarantola S, Saltelli A. Sensitivity and uncertainty analysis in spatial modelling based on GIS. Agriculture, Ecosystems \& Environment, 2000; 81(1):71-79.

45. Turányi T. Sensitivity analysis of complex kinetic systems. Tools and applications. Journal of Mathematical Chemistry, 1990; 5(3):203-248.

46. Saltelli A. Sensitivity analysis: Could better methods be used? Journal of Geophysical Research: Atmospheres (1984-2012), 1999; 104(D3):3789-3793.

47. De Moel H, Asselman NEM, Aerts JCJ. Uncertainty and sensitivity analysis of coastal flood damage estimates in the west of the Netherlands. Natural Hazards and Earth System Sciences, 2012; 12(4):1045-1058.

48. Saltelli A, Tarantola S, Chan K-S. A quantitative modelindependent method for global sensitivity analysis of model output. Technometrics, 1999; 41(1):39-56.

49. Ratto M, Tarantola S, Saltelli A. Sensitivity analysis in model calibration: GSA-GLUE approach. Computer Physics Communications, 2001; 136(3):212-224.

50. Simlab. Software Package for Uncertainty and Sensitivity Analysis. Joint Research Centre of the European Commission, 2011. Available at: http://simlab.jrc.ec.europa.eu, Accessed October 2, 2014.
51. Sobol' IM. Global sensitivity indices for nonlinear mathematical models and their Monte Carlo estimates. Mathematics and Computers in Simulation, 2001; 55(1-3):271-280.

52. Huizinga HJ. HSRR02: Water Safety: Flood Depth and Extent, 2010.

53. Eding G, Oosterhaven J, de Vet B, Nijmeijer H. Constructing regional supply and use tables: Dutch experiences. Pp. 237262 in Understanding and Interpreting Economic Structure. Berlin/Heidelberg: Springer, 1999.

54. Nijdam M, der Lugt L, De Jong O. Havenmonitor 2012: de economische betekenis Nederlandse zeehavens, 2014.

55. Ward PJJ, De Moel H, Aerts JCJH, Glade T. How are flood risk estimates affected by the choice of return-periods? Natural Hazards and Earth System Sciences, 2011; 11(12):31813195.

56. Hallegatte S, Ranger N, Mestre O, Dumas P, Corfee-Morlot J, Herweijer C, Wood RM. Assessing climate change impacts, sea level rise and storm surge risk in port cities: A case study on Copenhagen. Climatic Change, 2011; 104(1):113-137.

57. Ranger N, Hallegatte S, Bhattacharya S, Bachu M, Priya S, Dhore K, Rafique F, Mathur P, Naville N, Henriet F, Herweijer C, Pohit S, Corfee-Morlot J. An assessment of the potential impact of climate change on flood risk in Mumbai. Climatic Change, 2011; 104(1):139-167.

58. Dutta D, Herath S, Musiake K. A mathematical model for flood loss estimation. Journal of Hydrology, 2003; 277(1):2449.

59. Förster S, Kuhlmann B, Lindenschmidt K-E, Bronstert A. Assessing flood risk for a rural detention area. Natural Hazards and Earth System Science, 2008; 8(2):311-322. 